Review Article

\title{
A Review of Pharmaceutical Recombinant Proteins and Gene Transformation Approaches in Transgenic Poultry
}

\author{
Sepideh Fallahi ${ }^{1}$, Reza Mohammadhassan ${ }^{2}$ \\ 1 Animal Science Department, Amino Techno Gene Private Virtual Lab (NGO), Tehran 1495845983, Iran \\ ${ }^{2}$ Plant Science Department, Amino Techno Gene Private Virtual Lab (NGO), Tehran 1495845983, Iran
}

Article history:

Submission September 2019

Revised January 2020

Accepted February 2020

*Corresponding author:

E-mail: sepide.fallahi@gmail.com

\begin{abstract}
Transgenic animals are employed to synthesize pharmaceutical recombinant proteins for three decades. There are many problems to use farm mammalian animals for recombinant production such as high cost of production and maintenance, long generation interval, toxic effects of some human-source pharmaceutical proteins in other mammalian and incompatibility of human-source glycosylation with the other mammalian' glycosylation that all lead to low efficiency. Thus, transgenic poultry has been considered as the bioreactor of recombinant protein production. Increasing demand for pharmaceutical human proteins caused to make considerable efforts to develop transgenic poultry producing eggs contain recombinant protein. In the present review, at the first, transgenic animal and poultry are compared for their benefits and limitations. Then, the protein content of the egg, the features, gene and promoter of the egg are studied. After that, the recent achievements of the producing pharmaceutical recombinant proteins are considered. In the following, there are some explanations about gene transformation approaches in poultry, including sperm-, testis-, PGCs, and blastocyst-mediated methods depending on CRISPR/Cas9, Retroviral vectors, and DNA microinjection techniques, and embryonic manipulation approaches such as windowing and Ex ovo for introducing and injecting transformed cells into eggs.
\end{abstract}

Keywords: Transgenic Poultry, Bioreactor, Pharmaceutical Recombinant Proteins, Transgenic Egg, Human-Source Protein Drugs, Poultry Transformation

\section{Introduction}

Transgenic animals can be employed as bioreactors to produce pharmaceutical proteins. Recombinant DNA technology has fundamentally been made changes to produce pharmaceutical proteins [1]. In gene transformation, a DNA fragment encoding a protein is digested by restriction enzymes then ligated to a vector digested by the same enzymes [2]. According to length of the target gene, there are several vectors. In addition to the target gene, each vector includes a promoter and a reporter gene. After constructing a vector, it is transferred to a single cell. Then the cell is cultured in specific medium to grow and divide. This process causes to replicate the gene. Simultaneously, the replicated genes are expressed to produce a lot of the recombinant proteins. After that, these proteins are extracted from the cells [3]. Disarmed viruses can be used as vectors as an ideal system to transform poultry; because they can easily and cheaply multiply to enhance target protein synthesis. Moreover, they facilitate the protein purification more efficiently. There are three prominent approaches to transform animals; using bacteria, fungi and mammalian cell, nevertheless, none of them are as effective as virus [4]. Bacterial system, such as Escherichia coli which can easily and rapidly multiply and produce protein, needs huge budget that prevents pervasive development. On the other hand, bacteria are not susceptible to produce complex protein components rapidly and make Post-translation modification to activate proteins biologically [1]. Fungi system, such as

How to cite:

Fallahi S, Mohammadhassan R (2020) A Review of Pharmaceutical Recombinant Proteins and Gene Transformation

Approaches in Transgenic Poultry. Journal of Tropical Life Science 10 (2): 163 - 173. doi: 10.11594/jtls.10.02.09. 
penicillin production, can grow better than bacteria, whilst there are some limitations on complex protein production [5]. Mammalian cell culture system could eliminate the limitations, although there can still be some problems, including slow growth, low purity of purified protein and high costs [6]. These limitations and increasing demand to produce pharmaceutical proteins have caused recent developments of transgenic animals as bioreactors. Milks of transgenic farm animals such as cow; sheep, goat and even pig contain recombinant productions. Mammary glands have a high capacity to produce complex proteins efficiently, though there are some limitations for lactating animals' application such as long time to create a transgenic animal, high costs to purify target protein from milk and high maintenance costs [7]. These issues have persuaded scientists to seek for low-cost and proper methods. Nowadays, employing poultry as a bioreactor could be a new method to resolve the issue and produce pharmaceutical human-source proteins. Although transgenic poultry technology has been improved over a last decade, it is considerable that the pharmaceutical proteins which are purified from eggs have been a remarkable achievement of biotechnology industry [3].

\section{Benefits of Using Poultry as a Bioreactor}

As mentioned earlier, application of other bioreactors has been limited due to the lack of posttranslational modifications as a main problem. Dairy livestock and poultry are proper choices to resolve post-translational modification problems [8]. Some proteins require glycosylation for fixing their third structures. So, if glycosylation is inhibited, protein will be inappropriately folded, then precipitated in endoplasmic reticulum. Glycosylation is actually binding sugar units to biosynthesized proteins. This process causes to activate proteins physiologically and appropriately [9]. Glycosylation pathway in human is more similar to poultry than mammals. A study on glycosylation of immunoglobulin G (IgG) produced in milk and egg has reported that IgG which is biosynthesized in mammary glands of cow, sheep and goat contain N-Glycolylneuraminic acid (NGNA); While IgG produced in other mammalian species such as rabbit includes NGNA and N-Acetylneuraminic acid (NANA). In the research, it has been indicated that IgG in both human and poultry contains only
NANA [10]. Some proteins usually are not glycosylated in human. For instance, there is no $\alpha 3-1$ galactose in human, bonobo and other primate apes, whist it could be found in mammary glands of other mammalian species [11]. The Gene which encodes $\alpha 3-1$ galactose is deactivated in human. The glycoprotein injection can stimulate immune system of human. Since $\alpha 3-1$ galactose is not produced in poultry, potential risk of immune responses against recombinant pharmaceutical proteins reduced for the proteins which is biosynthesized in egg [12].

Dairy farm animals are remarkable model due to high gene expression in mammary glands and massive milk production. But there are some obstacles including long distance of generation, high-cost of breeding, uncontrollable environmental factors, biochemical resemblances which can cause toxicity in the animal. On the other hand, chemical composition of milk is so complex to purify recombinant protein; because the protein should be purified from high levels of lipids, liquids and internal proteins of milk. The main advantages of transgenic poultry for pharmaceutical proteins production are quick maturity, short distance of generation, high annual production of progeny, simple, low-cost and controllable breeding [13]. Poultry maturate six months after hatching and annually hatch 300-330 eggs. Provided that $100 \mathrm{mg}$ pharmaceutical protein could be produced per egg, it is probable that a hen would be able to produce $30 \mathrm{~g}$ of the protein per year. Chicks hatch out after 21 days. Each transgenic rooster can fertilize ten hens to generate 100,000 transgenic chicks [8]. Poultry can also tolerate high level of the proteins which are toxic for other animals. This ability has been caused by evolutionary gap between avian and mammals. These living creatures have taken distance during evolution; so, their biological systems have made different. Another point is that poultry can be maintained in isolated conditions. It is predicted that genetic engineering is susceptible of expressing $0.5 \mathrm{~g}$ recombinant protein per egg [14]. Cost of each gram of monoclonal antibody production has been reported 100, 20-22 and 0.1-0.25 US dollars in cell culture, transgenic goat and transgenic egg, respectively. Overall, the expenditure of production, recovery and extraction of recombinant proteins is so low in poultry due to simple Protein Complex in egg. In addition, recombinant protein concen- 
Table 1. Important proteins of egg white (albumen)

\begin{tabular}{ccc}
\hline Name & Weight (g) & $\%$ of total protein weight \\
\hline Ovalbumin & 2.2 & 54 \\
Ovotransferrin & 0.5 & 12 \\
Ovomucoid & 0.5 & 12 \\
Lysozyme & 0.15 & 3.4 \\
\hline
\end{tabular}

tration is higher in egg than other systems [15].

\section{Egg Proteins}

There are three main parts of egg including egg white or albumen (60\%), yolk (30\%) and eggshell (10\%; contains soft and hard layers). Albumin is the most important protein in white egg and has simple chemical structure. There are three main proteins which include 78 percent of total protein content of egg white such as ovalbumin (54\%), ovotransferrin (12\%), and ovomucoid (12\%), (Table 1) [16]. The proteins of egg white are less complex relatively to ease purification of recombinant protein from albumin. Nowadays, there can be found significant developments purify egg white proteins for commercial productions [17]. Egg white proteins are released from magnum cells, whilst some proteins of yolk are synthesized by liver and added to yolk by mediator receptors during the days before laying. When egg is moving along oviduct, release of egg white proteins is stimulated [18]. Although it has low concentration of lipids, yolk is the most prominent complex of lipids. This complex includes triglycerides, sterols (beneficial cholesterols), phospholipids and glycolipids [19]

\section{Regulatory Sequences for Gene Transforma- tion}

Poultry can be used as bioreactor of human source proteins which might be toxic for other mammals. Egg is appropriate to produce pharmaceutical proteins; because there is massive capacity of recombinant protein production. Recombinant proteins biosynthesized in albumin have long sustainability and half-life [3]. Gene of the protein which has been considered to produce should be integrated to gene of one of main egg white proteins. For this aim, regulatory sequences of the genes encoding egg white proteins should be used. Then a modified secretive promoter is employed to express target gene in egg white [12]. As it is mentioned above, ovalbumin and albumin are con- tained the highest percentages of egg white protein content and there are also many studies to investigate their molecular characteristics. So, they have been considered to use in gene transformation for expression in oviduct as the most suitable candidates. The regulatory sequences of the genes are so important for gene transformation. When ovalbumin is expressed, recombinant gene would simultaneously be expressed by the approach as same level as ovalbumin [20]. Indeed, there have been many studies to express target gene in yolk. The specific regulatory sequences which are involved in yolk proteins biosynthesis have been recognized [21]. As it was noticed, some yolk proteins are biosynthesized in liver. Hence, the recombinant gene should be transformed in liver to produce recombinant pharmaceutical protein in yolk [18].

It is possible that unpredictable result would be observed by application of the regulatory sequences. The transformed gene has not been expressed in G0 crossing and G1 crossing generations. The reason of the phenomenon has been reported gene silencing by researchers [22]. Gene silencing is a phenomenon that gene expression is reduced and/or stopped, but it will be possibly expressed again. This epigenetic and permanent phenomenon, but sometimes reversible, occurs in most transgenic organisms. It is caused by chromosome place effect (CPE). Overcoming gene silencing is one of the main issues in transgenic animals [23]. It has been reported that some genes resist against silencing, such as metallothionein gene locus in the mouse [24], ß-globulin and ßlacto globulin in human [25] and lysozyme in chicken. This characteristic of lysozyme gene shows that the regulatory elements of the gene can be employed to facilitate recombinant gene expression in egg white [26].

\section{Lysozyme Gene Characteristics}

Lysozyme is an enzyme found in saliva, tear and egg white. The enzyme is able to digest gram positive bacteria and some macromolecular polysaccharides. In fact, it causes bacteria death through digestion of membrane polysaccharides. Lysozyme gene contains regulatory sequence, promoter, signal peptide sequence, coding sequence of the protein (CDS) and terminal sections (Figure 1) [27].

The gene should be extracted from chicken to 


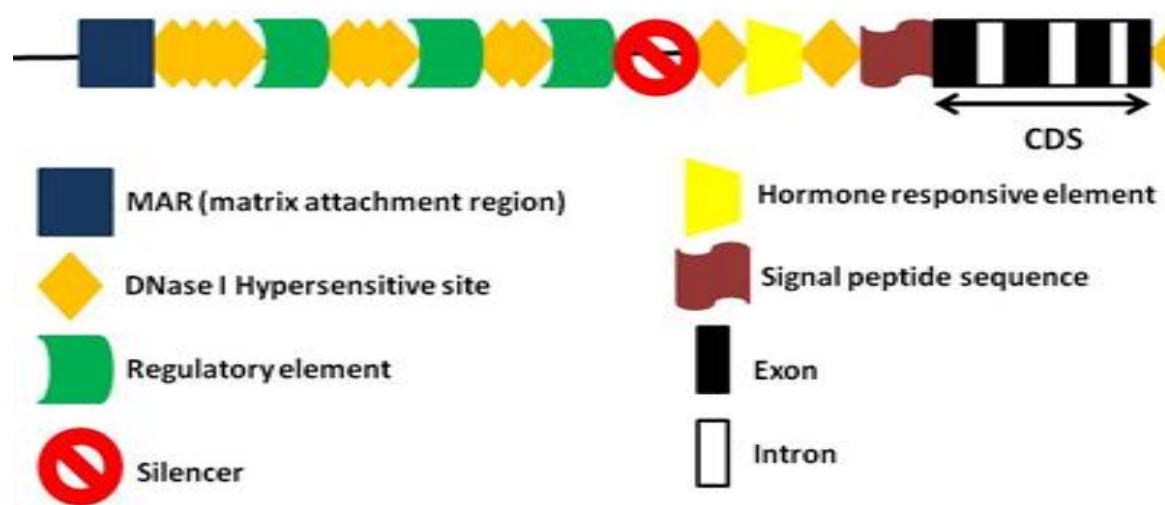

Figure 1. Lysozyme gene scheme

be applied in gene transformation. Then, the gene should be disarmed by removing CDS that the construct have been called IDIII-ko. After that, target gene can be integrated in IDIII-ko then in a vector. Finally, the vector is transferred into blastocyst [22].

The regulatory sequences of lysozyme gene are susceptible to resist CPE and gene silencing and express target gene after integration of the gene into the chicken genome. According to efficiency of lysozyme gene and the gene resistance to gene silencing, the gene has been improved by biotechnologists to use in gene transformation [26].

The gene expression can be regulated by acetylation of histone proteins which bind the gene. The H4 protein acetylation reduces the gene expression. Lysozyme gene expression is enhanced fivefold by acetylation of H2B, H2A and $\mathrm{H} 4$ during maturation of macrophage cells. Lipo polysaccharides cause to acetylate $\mathrm{H} 3$ to increase tenfold lysozyme gene expression [28].

\section{Recent Achievements}

There are many reports to use transgenic poultry, particularly chicken, for producing pharmaceutical recombinant proteins. US FDA have approved about 89 pharmaceutical proteins medications, produced by transgenic poultry, from 2011 to the end of 2017 [29]. Moreover, Yu et al. generated induced pluripotent stem cells of chicken from fibroblast cells for using a non-viral reprogramming method. These cells are able to enhance growth and are expressed high telomerase level [30]. The cells present an interesting tool to produce transgenic chicken. Transgenic chickens which were generated, are genetically suitable and stable to produce active recombinant human lysozyme. Also, a pipeline was provided to purify these recombinant proteins from transgenic eggs [14]. Liu et al. produced transgenic chickens that human neutrophil defensin 4 proteins were successfully expressed in the chickens' eggs [31]. Also, Park et al. could genetically transform chickens for producing human epidermal growth factor which was expressed by an oviduct-specific promoter [32]. It has been indicated that epithelial progenitor cells population are significantly susceptible to collaborate chicken oviduct epithelial cells in vitro culture as an effective model for development of avian bioreactors production [33]. Koo et al. succeeded in generating a transgenic chicken which was used as a bioreactor to express high level of human erythropoietin gene [34]. In another study, an oviduct bioreactor which was genetically transformed by recombinant avian adeno-associated virus (rAAAV) has been created as a convenient and efficient to produce recombinant proteins [35]. Kidani et al. enable of expressing interferon-inducible transmembrane proteins to prevent viral infection in transgenic chickens which were transformed by PGC method [36]. It has been recently reported that an anticancer monoclonal antibody was produced in transformed eggs of transgenic chickens to treat lymphoma cancer [37]. In a more recent study, human interferon beta gene ( $h I F N-\beta)$ was integrated into ovoalbumin locus of PGCs by CRISPR/Cas9 method to produce eggs which contain $h I F N-\beta$ [20]. Kwon et al. transformed human erythropoietin ( $h E P O)$ gene into oviduct to produce transgenic chicken eggs for expressing $h E P O$ in egg whites [38]. Human interferon $\alpha 2 a$, cytokine, and colony-stimulating factor genes have been trans- 


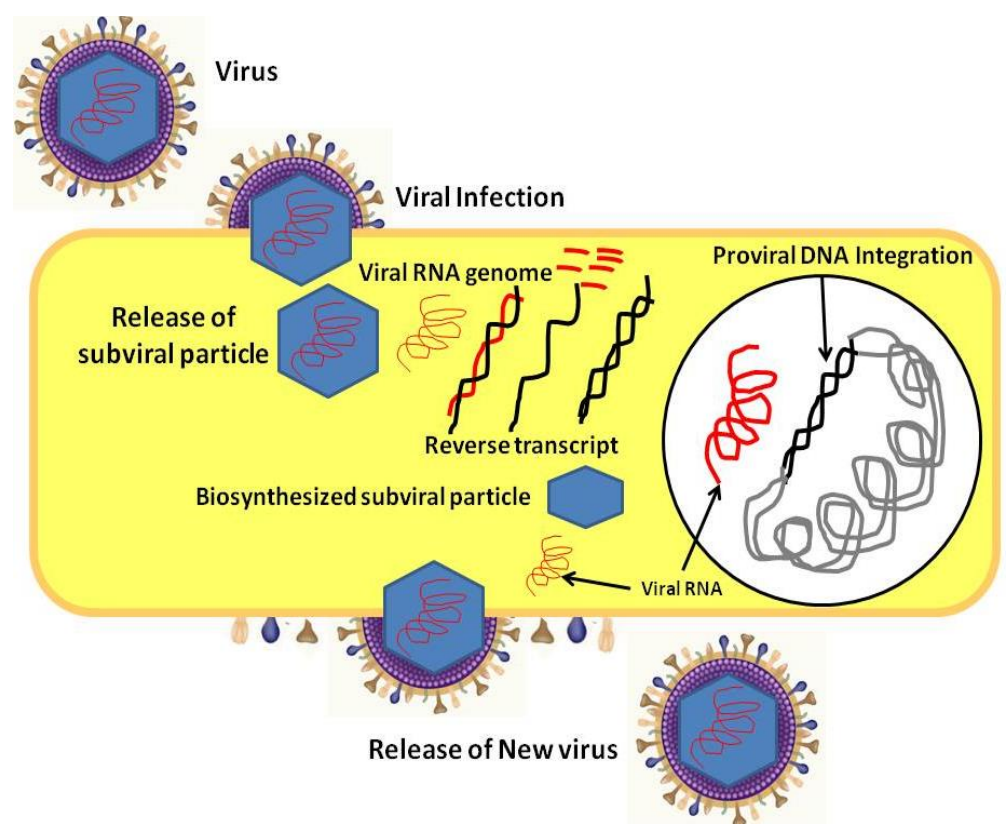

Figure 2. Retrovirus infection

ferred into chicken eggs as bioreactors for cost-effective expression and purification of their proteins [29].

\section{Gene Transformation Approaches in Poultry Spermatozoids}

At the beginning of the transgenic technique development, it seemed that spermatozoids are the only efficient heritable tools to transfer a foreign DNA fragment to animal genome. It has been indicated that mammalian spermatozoids are susceptible to bind to a foreign gene then are transferred to ovule, during fertilization [39]. A DNA fragment is generally bonded to a sperm which is employed to fertilize an ovule. Then the fragment is transferred to the ovule and the gene can be finally expressed in hatched chickens [40].

\section{DNA microinjection method}

Foreign DNA fragment can be transferred into cell nucleus by micropipette, in the method. The DNA could be most probably integrated into the animal genome. This method is employed to introduce foreign genes to progenitor nucleus of the mammalian recently fertilized ovule [41]. On the contrary, application of microinjection for avian transformation is more difficult than mammals'; because a recently laid egg contains 50000-60000 cells, approximately. However, it is possible for transformation of recently fertilized embryo. Mi- croinjected eggs are cultured on three-stage method (Ex ovo) to hatch [42].

\section{Retrovirus}

Retrovirus-mediated vectors are commonly and frequently used to transfer foreign gene into genomes of the poultry. It is possible to transform large number of cells by target gene due to high titers of the retrovirus [35]. Retrovirus contains RNA as the genome and a Protein coat (capsid) which includes integrase. The capsid binds to specific receptors on plasma membrane of host cell. Then subviral particle enters into the cytoplasm of host cell by receptors intermediation and endocytosis process. Viral genomic RNA is transcribed to cDNA which is capable to be transferred into the nucleus and integrated into the genomic DNA of host cell by integrase. The integrated genomic DNA is replicated by host cell DNA and inherited with regard to Mendelian genetic principles. Viral integrated DNA can lead to biosynthesis of a viral genomic RNA and proteins including a polymerase (pol) and membrane coating proteins (Env and gag). These proteins make a new virus capsid for packing the genomic RNA. This new complex is transferred to host cell membrane and released (Figure 2) [42].

Construction genes and packing sequences are not removed from some kinds of viral vectors to be able to multiply new viral particles and conse- 


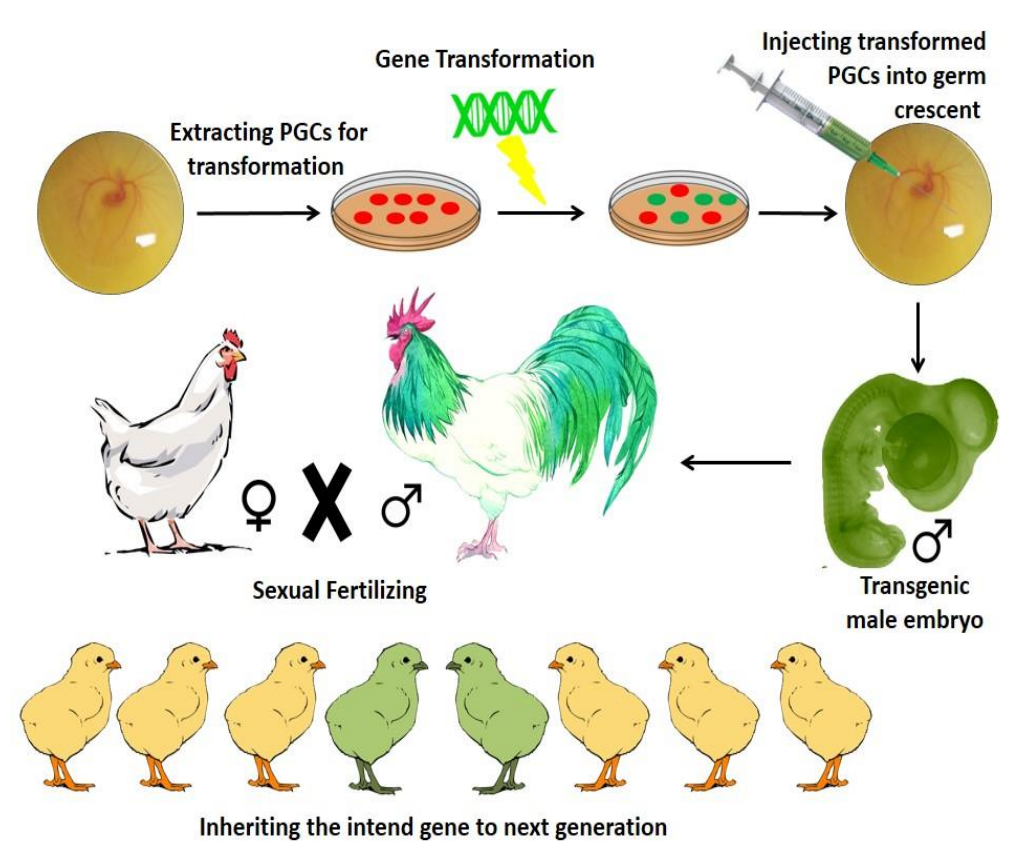

Figure 3. Transgenic chicken production by primordial germ cells; male transgenic poultry can fertilize more female to produce more transgenic chicks in next generation

quently infect more cells. Hence, retroviral vectors which can multiply are susceptible to infect easily sufficient number of germ cells and transfer intended gene to second generation and, subsequently, next generations. But chicken transformation by replicable retroviral vectors could release virus to environment [43]. In contrast, there are non-replicable retroviral vectors which not contain pol, gag and Env genes as vital factors for multiplication. The vectors reproduce new defective virus which capable of reducing environmental contamination. Also, these retroviral vectors can just infect host cell but not multiply. Defective virus can transfer more $10 \mathrm{~kb}$ length DNA fragments; because their vital replication genes are removed. Modern retroviral vectors have been developed and cause minimum environmental contamination with regard to new strategies [12].

\section{Direct DNA transformation to testicles}

The method was reported in 1995. But low potential of foreign DNA transformation into testicle tissue is considered as a restriction factor of this method application [44].

\section{Blastocyst}

Blastocysts are very effective in gene transformation. The cells are easily transferred from donor animal to receiver and play role in formation of somatic and sexual (germ line) tissues. These cells can be maintained in cell culture medium many days. Also, expression of transferred gene into blastocyst could be evaluated before transforming embryo. With these characteristics, cells are considered as ideal vectors for new genetic modification of germ line [45]. Blastocysts are extracted and modified and finally enter a growing embryo to produce a chimeric embryo contains an intended gene [46].

\section{Primordial germ cells}

Primordial germ cells (PGC) have been used as a suitable method for poultry gene transformation, since these cells were recognized as basic cell which produce spermatozoa and ovule. Primordial germ cells are the origin of germ line in poultry. At the first stage of embryonic differentiation, these cells can be extracted from germ crescent, a region out of the embryo. PGCs migrate from germ crescent to gonadal ridge of embryo to produce germ line structure [47]. Final destination of every genome modification is germ line; because they are susceptible to inherit transferred gene. Gene transformed primordial germ cells of chicken can be multiplied in a medium containing growth factors to produce transgenic poultry. Genetically transformed PGCs, retrovirus and blastocysts are injected to germ crescent of recent ferti- 


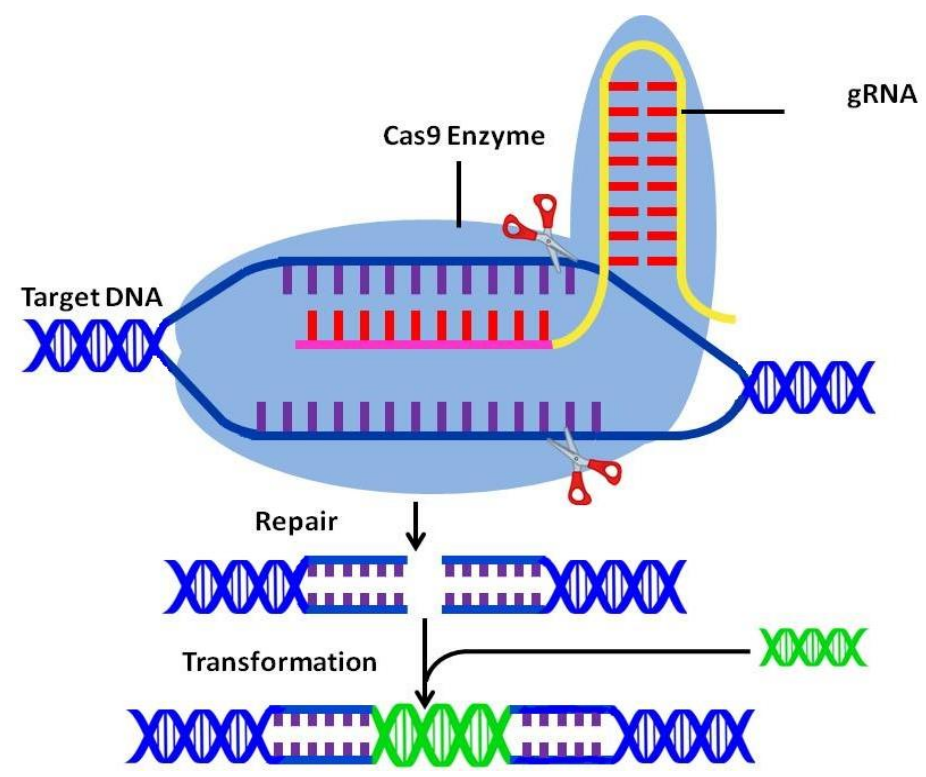

Figure 4. CRISPR/Cas9 method for gene transformation

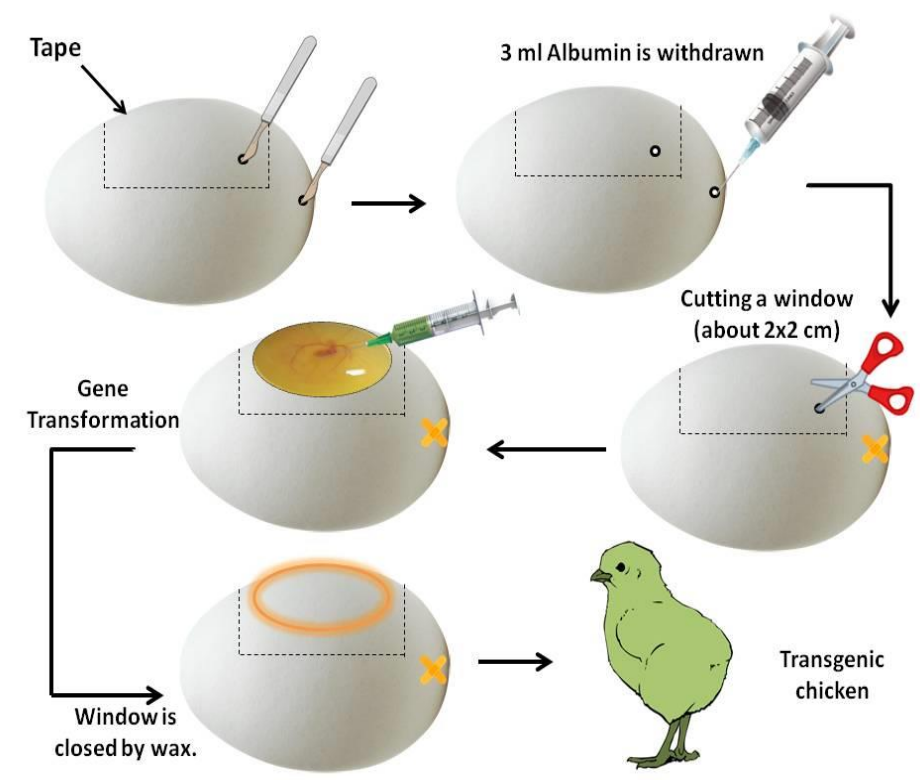

Figure 5. Windowing method for embryonic manipulation

lized egg to produce a transgenic chicken which is able to inherit transferred gene to next generations (Figure 3). PGCs and retrovirus are generally con sidered as common practical methods for gene transformation of poultry [48].

\section{CRISPR/Cas9}

Clustered regularly interspaced short palindrodromic repeats/ CRISPR associated protein 9 (CRISPR/Cas9) has been observed as microbial immune system to protect bacteria against bacteriophages and offensive plasmids. CRISPR/Cas9 system has been generally classified as three cate- gories regard to Cas9 protein structure and their gene sequence. CRISPR/Cas9 which has been employed for accurate and purposeful gene editing is included type II system [49]. CRISPR/Cas9 has two main parts; an endonuclease and short guide RNA (gRNA) sequence. The endonuclease is known as Cas9 which is extracted from Streptococcus pyogenes. There is gRNA to guide Cas9 toward target gene. Cas9 can digest double strain DNA as blunt end, as soon as the enzyme binds to the target sequence. Then an intended gene can insert between two digested sequences (Figure 4). Currently, this approach is widely used to produce 


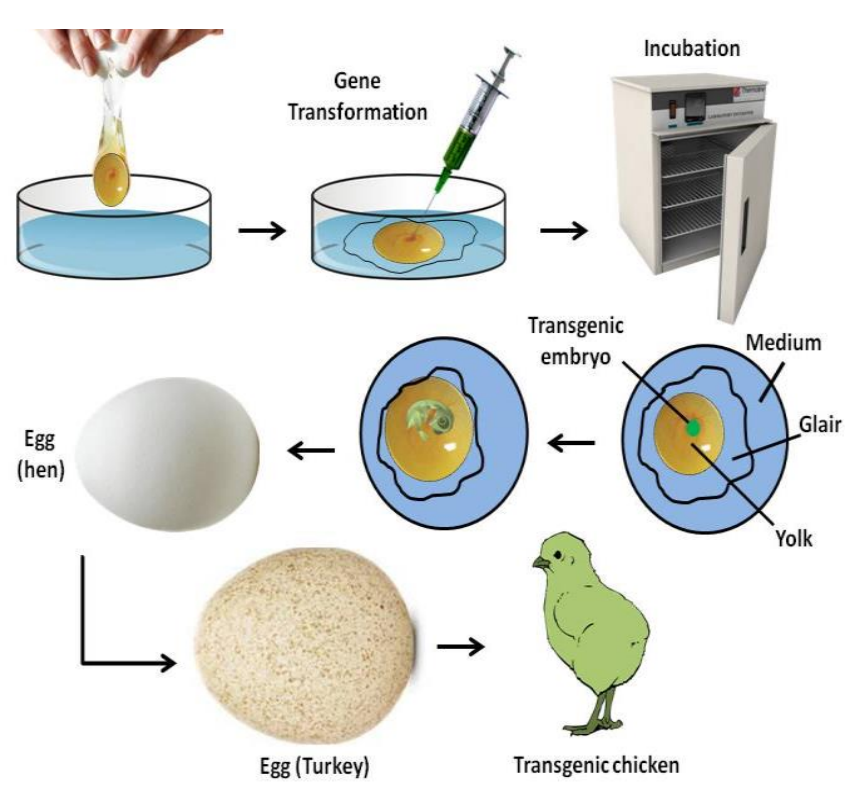

Figure 6. Ex ovo method for embryonic manipulation

Table 2. Benefits and limitations of the methods for poultry transformation

\begin{tabular}{|c|c|c|c|}
\hline \multicolumn{2}{|c|}{ Method } & Benefit & limitation \\
\hline \multicolumn{2}{|c|}{ Spermatozoid-mediated } & Low cost, ease of use, high efficiency [53] & $\begin{array}{l}\text { Low repeatability, depending on } \\
\text { non-specific techniques [40] }\end{array}$ \\
\hline \multicolumn{2}{|c|}{ DNA microinjection } & $\begin{array}{l}\text { Ability for transformation of the recent ferti- } \\
\text { lized embryo [42] }\end{array}$ & $\begin{array}{l}\text { Expensive, laborious, 1-4\% suc- } \\
\text { cess rate, random DNA integra- } \\
\text { tion [53] }\end{array}$ \\
\hline \multicolumn{2}{|c|}{ Retroviral vector } & $\begin{array}{l}\text { Transforming large number of cells, specific } \\
\text { host, transferring more than } 10 \mathrm{~kb} \text { gene, low } \\
\text { environmental contamination [12] }\end{array}$ & Gene silencing [53] \\
\hline \multicolumn{2}{|c|}{ Testicle cell-mediated } & Producing transgenic sperms [40] & Low potential [40] \\
\hline \multicolumn{2}{|c|}{ Blastocyst- mediated } & $\begin{array}{l}\text { High efficiency, ideal vector to transfer gene } \\
\qquad[46]\end{array}$ & $\begin{array}{c}\text { Depending on non-specific tech- } \\
\text { niques [46] }\end{array}$ \\
\hline \multicolumn{2}{|c|}{ PGC mediated } & Ability to inherit gene [48] & $\begin{array}{c}\text { Depending on non-specific tech- } \\
\text { niques [46] }\end{array}$ \\
\hline \multicolumn{2}{|c|}{ CRISPR/Cas9 } & $\begin{array}{c}\text { Specific gene and even single nucleotide } \\
\text { modification [20] }\end{array}$ & $\begin{array}{c}\text { Probability of off-targets effects } \\
\text { [20] }\end{array}$ \\
\hline \multirow{2}{*}{$\begin{array}{l}\text { Embryonic } \\
\text { Manipula- } \\
\quad \text { tion }\end{array}$} & $\begin{array}{l}\text { Window- } \\
\text { ing }\end{array}$ & High hatchability [54] & $\begin{array}{l}\text { Possibility of embryo infection } \\
\qquad[54]\end{array}$ \\
\hline & Ex ovo & $\begin{array}{l}\text { High hatchability, transforming two-hour } \\
\text { fertilized egg [54] }\end{array}$ & $\begin{array}{l}\text { Possibility of embryo infection } \\
\text { [54] }\end{array}$ \\
\hline
\end{tabular}

transgenic chicken as bioreactor [20].

\section{Embryonic Manipulation}

There is a main problem for application of aforementioned methods to produce transgenic poultry and embryonic manipulation; because creating an acceptable multiplicity of G0 descendants requires achieving a proper hatchability. Methods and techniques of embryonic manipulation have been developed for this purpose [50]: 


\section{Classical method}

There is a classical method to manipulate embryo; firstly, a window is opened on the eggshell. Secondly, embryo is genetically manipulated. Finally, the window is closed by wax and shell. Hatchability of the method is very low. There can be found a well-developed method with optimum hatchability, known as "windowing method" to produce transgenic poultry [51].

2. Windowing

The recent laid eggs are collected in the method. First of all, the bottom of eggshell is pierced to withdraw some albumin. Then a window is opened on eggshell and embryo is genetically manipulated. Finally, the window is coated by phosphate buffered saline and closed by eggshell and wax (Figure 5). Hatchability can be improved about $6-30 \%$ by the windowing method. Providing that retroviral vectors are employed in the method; hatchability will be improved about 23-35\% [52].

3. Three-stage medium (Ex ovo)

This method enables researchers to transfer an intended gene to primary embryo of recent fertilized egg, collected from hen oviduct two hours after fertilization, as well as recent laid eggs. The transformed egg is incubated in medium which contains synthetic pseudo-oviduct liquid for 18-24 hours and $37.5^{\circ} \mathrm{C}$ and rotated $90^{\circ}$ every ten minutes. During incubation, it is transferred into a receiver (step-mother) eggshell without any air chamber. After 2-4 days, the embryo is transferred into a larger eggshell, usually turkey eggshell with a small air chamber (Figure 6).

There are about 60000 cells in transgenic embryo at the end of the first stage of the method. The second stage includes embryo growth and development period. This egg is hatched as same as wild egg [4]. The benefits and limitations of the all approaches for gene transformation in poultry are summarized in Table 2.

\section{Conclusion}

There is a high potential for poultry to produce pharmaceutical recombinant proteins. Nowadays, poultry could resolve difficulties of transgenic animal, particularly glycosylation, as bioreactor. It is notable that glycosylation process in poultry is approximately as same as human. Also, poultry transformation is more low-cost than animals', as well as recombinant protein expression and purification, specifically when the protein is massively produced in eggs. The promoter of the lysozyme can be utilized for easy and high protein expression in egg whites. There are many pharmaceutical recombinant proteins, extracted from transgenic poultry and eggs, which have been approved by US FDA as protein drugs. Eggs are usually transformed by several approaches including Sperm-, testis-, PGCs-, and blastocyst-mediated methods depending on CRISPR/Cas9, Retroviral vectors, and DNA microinjection techniques. The transformed PGCs and blastocysts could be injected into eggs by embryonic manipulation approaches, especially windowing and Ex ovo. Generally, PGCs, retrovirus, and recently CRISPR/Cas9 are common and beneficial ways for gene transformation in poultry, as well as Ex ovo for transferring transgenic PGCs into eggs, although there are some limitations for all approaches.

Finally, there is a correlation between proportions of egg production and increasing pharmaceutical recombinant proteins, it is recommended that natural structures of the proteins in different level of expression and laying egg could be investigated, and gene transformation can be effectively and specifically improved and developed for poultry transformation.

\section{Acknowledgment}

The authors would like to thank the Amino Techno Gene private virtual Lab for supporting the study.

\section{References}

1. Chen R (2012) Bacterial expression systems for recombinant protein production: E. coli and beyond. Biotechnology Advances 30 (5): 1102-1107.

2. Mohammadhassan R, Kashefi B, Delcheh, K S (2014) Agrobacterium-based vectors: a review. International Journal of Farming and Allied Sciences 3(9): 1002-1008.

3. Abeyrathne EDNS, Lee HY, Ahn DU (2013) Egg white proteins and their potential use in food processing or as nutraceutical and pharmaceutical agents-a review. Poultry Science 92 (12): 3292-3299.

4. Petitte JN, Mozdziak PE) 2014) Production of transgenic poultry. In Transgenic Animal Technology. 2014; Third Edition: 335-357.

5. Fleißner A, Dersch P (2010) Expression and export: recombinant protein production systems for Aspergillus. Applied Microbiology and Biotechnology 87 (4): 1255- 
1270.

6. Lai T, Yang Y, Ng SK (2013) Advances in mammalian cell line development technologies for recombinant protein production. Pharmaceuticals 6 (5): 579-603.

7. Bertolini LR, Meade H, Lazzarotto CR et al. (2016) The transgenic animal platform for biopharmaceutical production. Transgenic Research 25 (3): 329-343.

8. Lillico SG, McGrew MJ, Sherman A, Sang HM (2005) Transgenic chickens as bioreactors for protein-based drugs. Drug Discovery Today 10 (3): 191-196.

9. Jung ST, Kang TH, Kelton W, Georgiou G (2011) Bypassing glycosylation: engineering aglycosylated fulllength IgG antibodies for human therapy. Current Opinion in Biotechnology 22 (6): 858-867.

10. Raju TS, Jordan R (2012) E.. Galactosylation variations in marketed therapeutic antibodies. In MAbs 4 (3): 385391.

11. Taniguchi N, Honke K, Fukuda M (2011) Handbook of glycosyltransferases and related genes. New York, Springer Science \& Business Media.

12. Cao D, Wu H, Li Q et al. (2015) Expression of recombinant human lysozyme in egg whites of transgenic hens. PloS One 10 (2): e0118626.

13. Doran TJ, Cooper CA, Jenkins KA, Tizard ML (2016) Advances in genetic engineering of the avian genome: “Realising the promise”. Transgenic research 25 (3): 307 $-319$.

14. Wu H, Cao D, Liu T et al. (2015) Purification and characterization of recombinant human lysozyme from eggs of transgenic chickens. PloS One 10 (12): e0146032.

15. Sheridan C (2016) FDA approves' farmaceutical' drug from transgenic chickens.

16. Nimalaratne C, Wu J (2015) Hen egg as an antioxidant food commodity: A review. Nutrients 7 (10): 8274 8293.

17. Liu J, Jin Y, Lin S et al. (2015) Purification and identification of novel antioxidant peptides from egg white protein and their antioxidant activities. Food chemistry 175 : 258-266.

18. Stadelman WJ, Newkirk D, Newby L. (2017) Egg scienceand technology. New York, CRC Press.

19. Cherian G (2013) Egg enrichment with omega-3 fatty acids. In Food Enrichment with Omega-3 Fatty Acids. 288298. Elsevier.

20. Oishi I, Yoshii K, Miyahara D, Tagami T (2018) Efficient production of human interferon beta in the white of eggs from ovalbumin gene-targeted hens. Scientific Reports 8 (1): 10203.

21. Cindrova-Davies T, Jauniaux E, Elliot MG et al. (2017) RNA-seq reveals conservation of function among the yolk sacs of human, mouse, and chicken. Proceedings of the National Academy of Sciences 114 (24): 4753-4761.

22. Li JJ, Lu LZ (2010) Recent progress on technologies and applications of transgenic poultry. African Journal of Biotechnology 9 (24): 3481-3488.

23. Jonas S, Izaurralde E (2015) Towards a molecular understanding of microRNA-mediated gene silencing. Nature Reviews Genetics 16 (7): 421.

24. McDonald KA, Tsung A (2014) Use of Genetically Engineered Mice for Research. In Success in Academic Surgery: Basic Science: 171-178. Springer, London.

25. Sharp JA, Nicholas, K (2014) Molecular genetics of milk protein production. The Genetics of Cattle: 397.

26. Hwang YS, Han JY (2018) Transgenesis and Genome Editing in Poultry. In Application of Genetics and Genomics in Poultry Science. IntechOpen.

27. Tullio V, Spaccapelo R, Polimeni M (2015) Lysozymes in the Animal Kingdom. In Human and Mosquito Lysozymes: 45-57. Springer, Cham.

28. Sarkies P, Reams C, Simpson LJ, Sale JE (2010) Epigenetic instability due to defective replication of structured DNA. Molecular Cell 40 (5): 703-713.

29. Herron LR, Pridans C, Turnbull ML et al. (2018). A chicken bioreactor for efficient production of functional cytokines. BMC Biotechnology 18 (1): 1-12.

30. Yu P, Lu Y, Jordan BJ et al. (2014) Nonviral minicircle generation of induced pluripotent stem cells compatible with production of chimeric chickens. Cellular Reprogramming (Formerly" Cloning and Stem Cells") 16 (5): 366-378.

31. Liu T, Wu H, Cao D et al. (2015) Oviduct-specific expression of human neutrophil defensin 4 in lentivirally generated transgenic chickens. PloS one 10 (5): e0127922.

32. Park TS, Lee HG, Moon JK et al. (2015) Deposition of bioactive human epidermal growth factor in the egg white of transgenic hens using an oviduct-specific minisynthetic promoter. The FASEB Journal 29 (6): 23862396.

33. Stadnicka K, Bodnar M, Marszałek A et al. (2016) Efficient source of cells in proximal oviduct for testing nonviral expression constructs in the chicken bioreactor model and for other in vitro studies. Folia Biologic 64 (1): 37-46.

34. Wang W, Dong B, Yang F (2018) Avian Retrovirus-Mediated Tumor-Specific Gene Knockout. Current protocols in Molecular Biology 121 (1): 23-17.

35. Koo BC, Kwon MS, Kim D et al. (2016) Production of Germline Transgenic Chickens Expressing High levels of Recombinant hEPO using a MoMLV-based Retrovirus Vector. In The 16th International Symposium on Developmental Biotechnology: 164-164. 
36. Kidani S, Okuzaki Y, Kaneoka H et al. (2017) Expression of interferon-inducible transmembrane proteins in the chicken and possible role in prevention of viral infections. Cytotechnology 69 (3): 477-484.

37. Kim YM, Park JS, Kim SK et al. (2018) The transgenicchicken derived anti-CD20 monoclonal antibodies exhibits greater anti-cancer therapeutic potential with enhanced Fc effector functions. Biomaterials 167: 58-68.

38. Kwon MS, Koo BC, Kim D et al. (2018) Generation of transgenic chickens expressing the human erythropoietin (hEPO) gene in an oviduct-specific manner: Production of transgenic chicken eggs containing human erythropoietin in egg whites. PLoS ONE 13 (5): e0194721.

39. Suárez JP, du Plessis S, Cardona-Maya, WD (2018) Spermatozoa: A Historical Perspective. International Journal of Fertility and Sterility 12 (3).

40. Mu Y, Jiao M, Zhao Y et al (2018) Method for tracing exogenous DNA uptake in live spermatozoa and embryos. Polish journal of veterinary sciences: 2018.

41. Lee ES, Palazzo AF (2017) Assessing mRNA nuclear export in mammalian cells by microinjection. Methods 126: 76-85.

42. Kelder TP, Vicente-Steijn R, Poelmann RE et al. (2016) The avian embryo to study development of the cardiac conduction system. Differentiation 91 (4-5): 90-103.

43. Saez-Cirion A, Manel N (2018) Immune responses to retroviruses. Annual review of immunology 36: 193220.

44. Wakchaure R, Ganguly S, Praveen PK (2015) Transgenic Chicken and its Usefulness in Medical Microbiology and Immunology: A Review. Annals of Pharma Research 3 (3): 97-99.

45. Schlatt, S, Ehmcke, J. (2014) Regulation of spermatogenesis: an evolutionary biologist's perspective. In Seminars in Cell \& Developmental Biology 29: 2-16. Academic Press.

46. Okon, B, Ibom LA, Njume GN (2016) Transgenesis techniques and its application in poultry production. Global Journal of Agricultural Sciences 15 (1): 11.

47. Kagami H (2016) Perspectives on avian stem cells for poultry breeding. Animal Science Journal 87 (9): 10651075.

48. Nakamura Y (2016) Poultry genetic resource conservation using primordial germ cells. Journal of Reproduction and Development 62 (5): 431-437.

49. Han JY, Park YH (2018) Primordial germ cell-mediated transgenesis and genome editing in birds. Journal of Animal Science and Biotechnology 9 (1): 19.

50. Ishino Y, Krupovic M, Forterre P (2018) History of CRISPR-Cas from encounter with a mysterious repeated sequence to genome editing technology. Journal of Bacteriology, JB-00580.

51. Naito M (2015) Embryo manipulation in chickens. The Journal of Poultry Science 52 (1): 7-14.

52. Farzaneh M, Attari F, Khoshnam SE, Mozdziak PE (2018) The method of chicken whole embryo culture using the eggshell windowing, surrogate eggshell and $e x$ ovo culture system. British Poultry Science 59 (2): 240244.

53. Suárez JP, Du Plessis SS, Maya WDC (2018) Spermatozoa: a historical perspective. International journal of Fertility \& Sterility 12 (3): 182.

54. Cloney K, Franz-Odendaal TA (2015) Optimized ex-ovo culturing of chick embryos to advanced stages of development. JoVE (Journal of Visualized Experiments) (95): e52129. 
This page is intentionally left blank. 
This page is intentionally left blank. 